\title{
NEW MATERIALS FOR PEDAGOGICAL TEACHING-LEARNING IN BIOCHEMISTRY: MONITORING PARTICIPATION
}

\author{
Campos, R.S. ${ }^{1}$; Fernandes, I.L. ${ }^{1}$; Andrade, G.P.V. ${ }^{1}$; Matta, L.D.M. ${ }^{1}$; Filgueira, \\ L.G.A ${ }^{1}$. \\ ${ }^{1}$ Departamento de Bioquímica, Centro de Biociências, Universidade Federal \\ do Rio Grande do Norte, RN, Brazil
}

This summary consists of an experience report about actions taken by biochemical monitors with pharmacy students. The reason of our work was the intention to both improve the process of teaching and also learning and invalidate the labels owned by biochemistry of hard and high-level-failure subject. The three actors: teachers, students and monitor could act on an integrated basis for the construction of an articulated $\mathrm{p}$ edagogical process between theory/practice and learning signification. Our main objective was to initiate the monitors in teaching practice effected through educational projects aimed at improving the teaching and learning of undergraduate courses and encouraging teacher training, involving teachers and students the guiding condition and monitors, respectively. $T$ he methodology was applied in three stages: 1) preparation of teaching materials; 2nd) application in class and 3rd) students rating of the methodology applied by monitors. The teaching materials presented discussed several biochemistry's topics and students had the opportunity to scaffold their own knowledge actively . Almost $90 \%$ considered the tool applied as highly related to classes and $82 \%$ considered this way of learning more significant than dialogical lectures. The performance of the monitors , focused on students and their learning, was considered great by students who were more motivated, resulting in the excellent evaluation of the work $(100 \%$ of acceptance $)$. The failure rate of the subject reduced in the four groups wherein the pedagogical materials were applied. It can demonstrate that both the mastery of scientific content and the pedagogical process involved during the teaching and learning moments are important. 